\title{
Extrativismo e Produção de Alimentos como Estratégia de Reprodução de Agricultores Familiares do Assentamento Seringal, Amazônia Meridional ${ }^{1,2}$
}

\author{
Keller Regina Soares ${ }^{3}$, Esvanio Edipo da Silva Ferreira ${ }^{4}$, \\ Santino Seabra Junior ${ }^{5}$ e Sandra Mara Alves da Silva Neves ${ }^{6}$
}

Resumo: A soberania alimentar do agricultor familiar está relacionada à transformação do agroecossistema, articulando a geração de trabalho e renda e sua capacidade de autoprodução de alimentos. Assim, este trabalho tem por objetivo investigar a produção de alimentos destinado ao autoconsumo e o extrativismo de látex realizados por agricultores familiares do assentamento de reforma agrária Seringal, no município matogrossense de Vila Bela da Santíssima Trindade, pertencente à Amazônia Meridional. Foram investigados agricultores familiares vinculados à Associação de Produtores de Látex (Aprolatex), através de entrevistas. Foi utilizado formulário semiestruturado abordando questões socioeconômicas e de produção. A heveicultura é a principal atividade agrícola exercida na unidade produtiva, correspondendo a até $65 \%$ da renda anual agrícola. O complemento da renda ocorre pela criação de pequenos animais, produção de leite e agricultura. As principais culturas produzidas são: mandioca, pepino, milho, abacaxi, batata doce e melancia, utilizados na alimentação familiar. A motivação para a produção para autoconsumo ocorre pela redução de despesas com compra de alimentos e a disponibilidades destes em quantidade e qualidade, garantindo a "segurança alimentar" dessas famílias. Os resultados demonstram a importância da produção de alimentos como estratégia para a permanência das famílias no campo e a necessidade de políticas públicas voltadas para a atividade extrativista.

Palavras-chaves: Agricultura familiar, autoprodução de alimentos, autoconsumo, reprodução social, segurança alimentar e nutricional, seringueiros.

1. Data de submissão: 11 de dezembro de 2016. Data de aceite: 25 de fevereiro de 2018.

2. Os autores agradecem o projeto de extensão "Núcleo de extensão em Desenvolvimento Territorial da grande Cáceres: uma estratégia de desenvolvimento sustentável por meio de ações que fortaleçam a produção agroecológica, agroindustrialização, comercialização e a atuação das mulheres", financiado no âmbito do Edital CNPq/MDA/SPM no11/2014 - Apoio à implantação e manutenção de núcleos de extensão em desenvolvimento territorial e à Capes.

3. Universidade do Estado de Mato Grosso. E-mail: kelleragronomia@hotmail.com

4. Universidade Federal de Mato Grosso - UFMT. E-mail: esvanioedipo@hotmail.com

5. Universidade do Estado de Mato Grosso (Unemat). Nova Mutum, Mato Grosso - Brasil. E-mail: santinoseabra@hotmail.com

6. Universidade do Estado de Mato Grosso (Unemat). Cáceres, Mato Grosso - Brasil. E-mail: ssneves@unemat.br 


\begin{abstract}
The food sovereignty of the family farmer is related to the transformation of the agroecossystem, articulating the generation of work and income and its capacity of self-production of food. Thus, this work investigates the production of food destined for self-consumption and latex extraction carried out by family farmers of the Seringal agrarian reform settlement, in Vila Bela da Santíssima Trindade, southern Amazonia. We investigated family farmers linked to the Association of Latex Producers (Aprolatex), through interviews. A semi-structured form was used addressing socioeconomic and production issues. Heveculture is the main agricultural activity in the production unit, accounting for up to $65 \%$ of annual agricultural income. The income supplement comes from the creation of small animals, milk production and agriculture. The main crops produced are cassava, cucumber, corn, pineapple, sweet potato and watermelon, which are also used in family food. The motivation for production for self consumption is the reduction of expenses with food purchases and their availability in quantity and quality, guaranteeing the "food security" of these families. The results demonstrate the importance of food production as a strategy for the permanence of families in the field and the need for public policies focused on extractive activity.
\end{abstract}

Key-words: Family agriculture, food self-production, self-consumption, social reproduction, food and nutrition security, tappers.

Classificação JEL: Q18.

DOI: http://dx.doi.org/10.1590/1234-56781806-94790560406

\section{Introdução}

O município de Vila Bela da Santíssima Trindade têm grande importância na história da formação do estado de Mato Grosso, por ter sido escolhida para sediar a capital do Estado em 1752. Segundo Canova (2008), a escolha do município para ser a primeira capital do Estado, se deu pela descoberta de jazidas de ouro no local e, principalmente, por sua localização à margem do rio Guaporé, sendo assim considerado um ótimo lugar para se difundir a economia estadual. Enquanto foi capital, a cidade obteve progresso devido aos investimentos em infraestrutura e incentivos fiscais para os novos moradores. No entanto, as dificuldades de povoar a região (distância, doenças e falta de rotas comerciais) e o estabelecimento de um importante centro comercial em Cuiabá acabaram forçando a transferência da capital em 1835, para Cuiabá; dessa forma, os moradores abandonaram a região, deixando casas, estabelecimentos comerciais e escravos para trás (MENDONÇA, 1982).

Atualmente, o município de Vila Bela da Santíssima Trindade apresenta grande diversidade de grupos sociais, como remanescentes de escravos (quilombolas), grupos indígenas, seringueiros, pequenos agricultores migrantes das regiões Sul e Sudeste do País, e grandes pecuaristas (LIMA et al., 2015). Dentre os diferentes grupos sociais existentes no município, alguns, como os extrativistas, atuam na agricultura familiar (MEDEIROS e LEITE, 1999).

A principal atividade econômica do município baseia-se na pecuária leiteira e sistema de cria e recria, fazendo com que o município ocupe a colocação de segundo maior produtor de gado no Estado (IBGE, 2010). Além da atividade pecuária, a agricultura têm alcançado destaque na região, principalmente com as lavoras de soja e de milho que vêm sendo cultivadas principalmente em grandes propriedades, cabendo a agricultura familiar a responsabilidade pelos cultivos de feijão, mandioca, banana e amendoim (LIMA et al., 2015).

No Brasil, a agricultura familiar é responsável pelo abastecimento interno de alimentos, sendo esses agricultores também os principais responsáveis pela conservação da agrobiodiversidade. Conforme apontamentos de Oler (2012), os maiores geradores e detentores da biodiversidade agrícola mundial são os agricultores familiares pertencentes a populações tradicionais. A autora segue afirmando que outros núcleos de agricultores familiares, como os assentamentos rurais, devem ser considerados como potenciais mantedores da agrobiodiversidade.

Manter a agrobiodiversidade é uma estratégia fundamental, principalmente quando adotada por agricultores familiares, pois a adoção de monocultivos em grande escala consolida paisagens cada vez mais 
simplificadas e vulneráveis, com baixas diversidade genética, e eficiência energética, e susceptível ao ataque de pragas e doenças, gerando um incremento na utilização dos agrotóxicos (ALTIERI, 2002). Junto a isso, a biodiversidade agrícola contribui na segurança alimentar desses agricultores com a oferta em quantidade e qualidade de alimentos que, segundo Belik (2003), é o direito à alimentação na quantidade adequada, ao consumo de alimentos de qualidade, bem como à regularidade no acesso aos alimentos.

A agricultura familiar, além de movimentar o mercado local com a comercialização da produção, também garante soberania alimentar dos agricultores pelo cultivo, visando autoconsumo. Essa é uma estratégia de diversificação da alimentação que contribui diretamente com sua segurança alimentar, sendo um dos elementos estratégicos do desenvolvimento sustentável da agricultura familiar, capaz não apenas de gerar rendimentos financeiros aos assentados, como também gerar benefícios mais amplos para a sociedade, relativos à segurança alimentar (GAVIOLI e COSTA, 2011). Essa produção para o autoconsumo também se converte em renda, principalmente porque reduz as despesas com manutenção alimentar (DESER, 2004).

$\mathrm{O}$ agricultor extrativista exerce uma modalidade importante dentro da agricultura familiar. O extrativismo é a maneira de produzir bens em que os recursos naturais úteis são retirados diretamente da sua área de ocorrência natural, sendo empregada baixa tecnologia quando exercido por populações rurais pobres de áreas "remotas" (DRUMMOND, 1996).

Na região de Vila Bela da Santíssima Trindade está localizado o assentamento Seringal, fundado em 18 de abril de 1997, e estabelecido na fazenda Santa Rosa. As principais atividades desenvolvidas na fazenda antes de a área se tornar assentamento de reforma agrária eram cria, recria e engorda de gado nelore e a extração de látex. A área total da fazenda é de 3.700 hectares (ha), distribuídos em 3.160 ha em pastagens e benfeitorias e em 540 ha de seringal. Para a escolha das famílias assentadas foi dada prioridade às 38 famílias que trabalhavam na extração de látex na propriedade, e as demais faziam parte de uma lista de espera do Instituto Nacional de Colonização e Reforma Agrária (Incra), totalizando 242 famílias assentadas. Atualmente, existem 89 famílias que fazem extração de látex, vinculadas à Associação de Produtores de Látex (Aprolatex). O tamanho do lote de cada agricultor familiar é de
13,05 ha, e os que fazem extração contam com a concessão de uso de mais 5,45 ha de seringal.

O extrativismo praticado pelos agricultores familiares não é mera coleta, mas se insere num conjunto mais amplo de relações econômicas, sociais e culturais que as unidades familiares estabelecem com o mercado, com a sociedade e com a natureza (REGO, 1999). A combinação do extrativismo com atividades agropecuárias desenvolvidas no assentamento Seringal têm possibilitado melhor qualidade de vida a esses agricultores, pelo aumento do poder de compra destes, pela renda obtida através do extrativismo e ainda por proporcionar alimentos diversificados a essas famílias.

Desta forma, neste trabalho o objetivo é investigar como a produção de alimentos destinado ao autoconsumo e a produção extrativista de látex realizados por agricultores familiares do assentamento de reforma agrária Seringal, no município matogrossense de Vila Bela da Santíssima Trindade, pertencente a Amazônia Meridional brasileira, influenciam na estratégia de reprodução social no assentamento.

\section{Metodologia}

\section{1. Área de estudo}

O município de Vila Bela da Santíssima Trindade tem área de $13.421,00 \mathrm{~km}^{2}$, está localizado entre as coordenadas geográficas: latitude $14^{\circ} 02^{\prime} 00^{\prime \prime}$ e $16^{\circ} 14^{\prime} 00^{\prime \prime}$ Sul e longitude $59^{\circ} 24^{\prime} 00^{\prime \prime}$ e $60^{\circ} 33^{\prime} 40^{\prime \prime}$ Oeste, na bacia do Alto Guaporé, afluente do Madeira Mamoré, bacia amazônica (Figura 1). Seu território está distribuído em dois biomas, 94\% no Amazônia e 6\%, no Cerrado. Encontra-se na região de transição entre os domínios morfoclimáticos e fitogeográficos Amazônico e do Cerrado (AB'SABER, 2002).

Em 2010, a população foi estimada em 14.493 habitantes, correspondendo a densidade demográfica de 1,08 habitante por $\mathrm{km}^{2}$, com índice de desenvolvimento humano (IDH) de 0,715 (IBGE, 2010). No município existem oito comunidades tradicionais de Chiquitanos, totalizando 190 famílias, três comunidades quilombolas com 60 famílias e dez assentamentos de reforma agrária do Instituto Nacional de Reforma Agrária (Incra/MT), com 1.120 famílias e um assentamento agrário via Crédito Fundiário com 80 famílias, totalizando 1.450 agricultores familiares (IBGE, 2010). 
648 - Extrativismo e Produção de Alimentos como Estratégia de Reprodução de Agricultores Familiares do Assentamento Seringal, Amazônia Meridional

Figura 1. Assentamento Seringal, nos contextos da região sudoeste de Planejamento do estado de Mato Grosso e do município de Vila Bela da Santíssima Trindade - MT

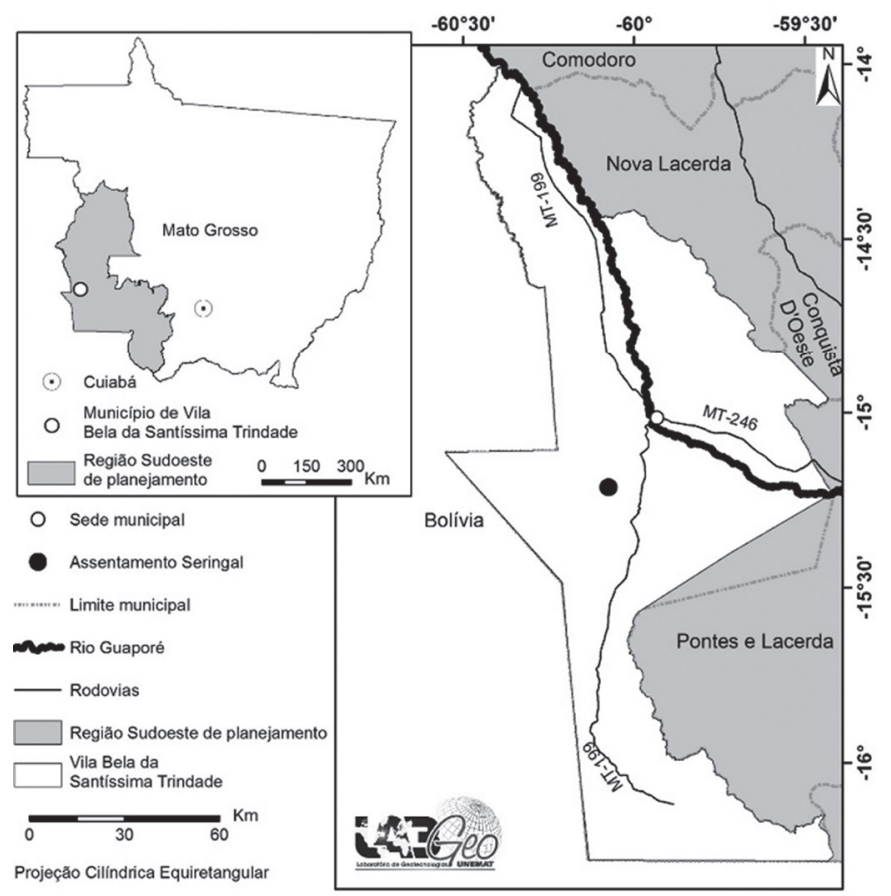

Fonte: LabGeo Unemat (2016).

O assentamento de reforma agrária Seringal tem 242 famílias assentadas, com população estimada de 1.089 habitantes, estando localizado na zona rural do município, a aproximadamente $35 \mathrm{~km}$ do centro da cidade. $\mathrm{O}$ assentamento foi criado em 18 de abril de 1997, através da compra da fazenda Santa Rosa pelo Incra, atendendo aos pressupostos da política de reforma agrária. Dentre as 242 famílias assentadas, 86 fazem parte da Associação de Produtores de Látex (Aprolatex), possuindo duas unidades de produção: a primeira, o lote de assentamento com 13,05 ha e a segunda, o lote de concessão de uso do seringal com 5,45 ha. A área do seringal existia antes da implantação do assentamento, onde ocorria plantio.

Devido à importância do extrativismo desenvolvido simultaneamente com atividades agropecuárias para esses agricultores, optou-se em trabalhar com os 86 agricultores familiares vinculados à Aprolatex.

\subsection{Procedimento metodológico}

Neste estudo foi adotada a metodologia quanti-qualitativa, utilizando dados quantitativos com a fina- lidade de facilitar a análise dos mesmos, e procurando compreender fenômenos da realidade baseados em informações fornecidas pelos próprios sujeitos entrevistados. Ao definir o aspecto qualitativo do objeto estamos considerando como "sujeito de estudo: gente, em determinada condição social, pertencente a determinado grupo social ou classe com suas crenças, valores e significados" (MINAYO, 2000).

Foram realizadas três reuniões com os 86 agricultores familiares do assentamento de Seringal (objeto de estudo), vinculados à Aprolatex, no qual foi apresentada a proposta da pesquisa, o convite para a participação e solicitada autorização da divulgação dos dados fornecidos, através da anuência ao termo de consentimento livre e esclarecido.

Após a determinação do público, foi realizada a coleta de dados entre outubro e dezembro de 2015 e janeiro de 2016, através de uma entrevista realizada com cada um dos 86 agricultores. Na entrevista foi utilizado um formulário semiestruturado realizado com o agricultor responsável pela unidade de produção familiar. O formulário foi composto por 80 questões abertas e fechadas com abrangência na caracterização 
social, produtiva, seja agrícola ou de extrativismo, e a produção para autoconsumo, além do acesso a políticas públicas.

A entrevista foi realizada na unidade produtiva e, conforme Duarte (2004), esta transmite ao entrevistado a sensação de tranquilidade e liberdade para a expressão das suas ideias e vivências. A entrevista foi realizada tanto com homens quanto com mulheres, ficando a critério da família a indicação de quem responderia o questionário. Em algumas situações, houve interferência por parte dos moradores da unidade de produção familiar.

Foi realizado passeio dirigido (turnê guiada) nas unidades produtivas, com a finalidade de se observar a paisagem local bem como os sistemas de produção existentes no assentamento. Segundo Albuquerque e Lucena (2004), o método de passeio dirigido apresenta como principal característica o uso de estímulos visuais, com o objetivo de conseguir a maior quantidade de informações dessas unidades de produção.

A metodologia do passeio dirigido, também denominada como turnê guiada ou informante de campo, consiste em uma técnica de entrevista em campo, em que o informante aponta as características do sistema de produção. Os passeios dirigidos aconteceram nos locais destinados à produção de alimentos voltados ao autoconsumo dessas famílias. Para localização das sedes das unidades e caracterização das áreas de exploração agropecuária foram utilizados o Sistema de Posicionamento Global (GPS) e registro fotográfico.

Para a análise qualitativa, as informações foram classificadas em categorias, que são formadas de acordo com as variadas respostas obtidas na aplicação dos formulários. De acordo com Bardin (2004), a categorização é uma operação de classificação de elementos constitutivos de um conjunto, por diferenciação e, seguidamente, por reagrupamento segundo o gênero (analogia), com os critérios previamente definidos. Assim, a abordagem qualitativa recorre a indicadores não frequenciais susceptíveis de permitir inferências. As categorias são elaboradas e definidas de acordo com o conteúdo das falas dos agricultores da comunidade.

As informações qualitativas e quantitativas obtidas foram tabuladas em planilha eletrônica no software Excel e por meio das estatísticas de frequência absoluta $\left(F_{i}\right)$, que indica quantas vezes a opção foi selecionada pelos entrevistados, e a frequência relativa $\left(F_{r i}\right)$, que corresponde à razão entre a frequência absoluta e o número total de observações, expressa em percentual.

\section{Resultados e discussão}

Foi identificada uma quantidade superior de homens $(69,01 \%)$ responsáveis pela unidade de produção familiar quando comparado com o número de mulheres $(30,99 \%)$ com essa responsabilidade. Em ambos os gêneros, foi observado que houve uma frequência maior no grupo de idade entre 31 e 40 anos, sendo que $34,62 \%$ das mulheres e $31,67 \%$ dos homens estão alocados nesse grupo (Tabela 1). Entretanto, os indivíduos do sexo feminino apresentaram o menor número de indivíduos da faixa etária acima de 60 anos (7,69\%), já o menor número de homens está na faixa de até 30 anos de idade. A ocorrência de mulheres mais jovens sendo responsáveis por unidades produtivas pode ser explicada pelo fato de estas serem viúvas ou divorciadas, com filhos menores de idade. Essas mulheres permanecem no campo como forma de conseguir o sustento de sua família e por tradição, considerando que muitas são de origem rural.

Tabela 1. Distribuição de indivíduos segundo o estágio de vida e gênero, no assentamento Seringal, Vila Bela da Santíssima Trindade - MT

\begin{tabular}{l|cc|cc|cc}
\hline \multirow{2}{*}{$\begin{array}{c}\text { Idade } \\
\text { (anos) }\end{array}$} & \multicolumn{2}{c|}{ Feminino } & \multicolumn{2}{c|}{ Masculino } & \multicolumn{2}{c}{ Total } \\
\cline { 2 - 7 } & $F_{i}$ & $F_{r i}$ & $F_{i}$ & $F_{r i}$ & $F_{i}$ & $F_{r i}$ \\
\hline Até 30 & 7 & 26,92 & 4 & 6,67 & 12 & 11,27 \\
$31-40$ & 9 & 34,62 & 19 & 31,67 & 28 & 33,80 \\
$41-50$ & 3 & 11,54 & 15 & 25 & 18 & 21,13 \\
$51-60$ & 5 & 19,23 & 17 & 28,33 & 22 & 25,35 \\
Acima de 60 & 2 & 7,69 & 5 & 8,33 & 6 & 8,45 \\
Total & $\mathbf{2 6}$ & $\mathbf{1 0 0}$ & $\mathbf{6 0}$ & $\mathbf{1 0 0}$ & $\mathbf{8 6}$ & $\mathbf{1 0 0}$ \\
\hline
\end{tabular}

$F_{i}=$ frequência absoluta; $F_{r i}=$ frequência relativa $(\%)$

Fonte: Os autores (2016). 
650 - Extrativismo e Produção de Alimentos como Estratégia de Reprodução de Agricultores Familiares do Assentamento Seringal, Amazônia Meridional

Segundo Ribeiro e Oliveira (1999), a participação da mulher na agricultura familiar sempre foi subestimada, o que faz com que a maioria dos homens seja o chefe da unidade produtiva. Isto ocorre devido ao fato de as mulheres serem responsáveis pela reprodução social do grupo, sendo as atividades produtivas desenvolvidas por elas consideradas como parte das tarefas atribuídas aos papéis de mãe e esposa, consideradas "ajuda" e "complementares" àquelas desenvolvidas pelos homens. Segundo Melo e Sabbato (2000), as mulheres do meio rural têm a ideologia patriarcal muito mais introjetada em seu comportamento do que outras.

No que se refere à origem dos agricultores no assentamento Seringal, verificou-se um contingente expressivo de agricultores vindos do Sudeste do País. A maioria dos entrevistados é natural de São Paulo (30,23\%), Mato Grosso (23,25\%) e Minas Gerais $(17,44 \%)$. Os estados de Rondônia e Pernambuco aparecem com a mesma frequência $(9,86 \%)$ e os estados com menores números de representantes foram Rio Grande do Sul (7,04\%) e Ceará $(2,32 \%)$.

Na região sudoeste de Mato Grosso, muitos agricultores têm origem de Minas Gerais e São Paulo, como observado por Mendes et al. (2013), em estudo com as mulheres extrativistas na região sudoeste mato-grossense. Situação que pode ser justificada pelo fato de que a ocupação dessa região foi impulsionada pela ação estatal através dos programas de incentivo à modernização agropecuária e integração a outros mercados (CUNHA, 2000). O autor segue afirmando que, para essa região, a migração ocorreu a partir da década de 1990, ligada à distribuição de assentamentos de reforma agrária.
Sendo os agricultores entrevistados todos provindos de outras localidades, verificou-se que a grande maioria $(60,46 \%)$ chegou ao município entre 1991 e 2000. Observou-se também que 19,77\% destes chegaram à Vila Bela da Santíssima Trindade antes da década de 1970; 16,28\%, entre 2001 e 2010 e 3,49\%, após 2010 .

Quanto à questão da escolaridade, verificou-se, de modo geral, a predominância de baixo nível escolar, em que 38,03\% dos agricultores não concluíram o nível fundamental. O nível de escolaridade de acordo com o gênero (Tabela 2) é variável, em que as mulheres, de forma geral, apresentaram nível escolar superior à demonstrada pelos homens. Dentre os entrevistados, $44,90 \%$ dos homens não terminaram o Ensino Fundamental, contra $22,73 \%$ dos indivíduos do gênero feminino para esta classe.

Para Sant'Ana (2003), o baixo nível de instrução formal no meio rural é um dos fatores que dificulta o processo de inovação tecnológica, e ele cresce em importância quando se verifica a existência de analfabetos. Segundo o autor, quando o nível de escolaridade entre esposas e maridos é semelhante, o fator estrutural (falta de ensino em graus mais elevados) é o que determina a baixa escolaridade e não as diferenças de gênero. Trazendo essa afirmação para a realidade do assentamento Seringal, pode-se afirmar que o gênero foi fator determinante para a diferença do nível de escolaridade, tomando como pressuposto que ambos os gêneros tiveram a mesma chance de estudar nos seus mais diferentes graus, não sendo a falta de oferta do ensino um fator determinante para o baixo nível de escolaridade.

Entre os filhos dos agricultores estudados, 17\% fizeram o Ensino Fundamental, 9\% têm o Ensino

Tabela 2. Ordenamento do nível de escolaridade segundo o gênero, no projeto de assentamento rural Seringal no município de Vila Bela da Santíssima Trindade

\begin{tabular}{l|cc|cc|cc}
\hline \multirow{2}{*}{\multicolumn{1}{c}{ Nível de escolaridade }} & \multicolumn{2}{c|}{ Feminino } & \multicolumn{2}{c|}{ Masculino } & \multicolumn{2}{c}{ Total } \\
\cline { 2 - 7 } & $F_{i}$ & $F_{r i}$ & $F_{i}$ & $F_{r i}$ & $F_{i}$ & $F_{r i}$ \\
\hline Fundamental Completo & 5 & 19,23 & 15 & 25 & 20 & 23,26 \\
Fundamental Incompleto & 5 & 19,23 & 27 & 45 & 32 & 37,21 \\
Médio Completo & 9 & 34,61 & 6 & 10 & 15 & 17,44 \\
Médio Incompleto & 4 & 15,39 & 12 & 20 & 16 & 18,60 \\
Superior Completo & 2 & 7,69 & 0 & 0,00 & 2 & 2,33 \\
Superior Incompleto & 1 & 3,85 & 0 & 0,00 & 1 & 1,16 \\
Total & $\mathbf{2 6}$ & $\mathbf{1 0 0}$ & $\mathbf{6 0}$ & $\mathbf{1 0 0}$ & $\mathbf{8 6}$ & $\mathbf{1 0 0}$ \\
\hline
\end{tabular}

$F_{i}=$ frequência absoluta; $F_{r i}=$ frequência relativa $(\%)$.

Fonte: Os autores (2016). 
Médio incompleto, 48\% têm Ensino Médio completo, $11 \%$ têm Ensino Superior incompleto e 15\% estão cursando cursos de nível superior. Os jovens que moram na cidade, por conta de cursar faculdade, se mantêm com a ajuda dos pais agricultores familiares e através de trabalho fixo ou esporádico no comércio local.

Gomes (2004) apontou que agricultores familiares têm baixa escolaridade, e seus filhos apresentam uma suave evolução no parâmetro educação em comparação aos pais, mas que estão muito longe do ideal, em que poucos desses jovens concluíram o Ensino Fundamental e são raríssimos os que têm formação universitária.

Obstáculos de ordem econômica e cultural estão presentes na dificuldade de estudo dos jovens no campo, destacando-se: a escassez de recursos financeiros da família, que não lhes permite custear a passagem de ônibus até a cidade; a necessidade da presença mais permanente de jovens nas atividades agropecuárias; as dificuldades de acesso à escola em função das longas distâncias, a falta de transporte ou condição precária da estrada e o desinteresse pelo estudo, pois os conteúdos das disciplinas não estão adaptados à sua realidade social. Entretanto, ainda com maior peso está o entendimento de muitos jovens, e principalmente de seus pais, de que "para ser agricultor não é preciso estudar" (FERREIRA e ALVES, 2009).

Dos membros que trabalham fora da unidade produtiva familiar (UPF), 96\% são filhos dos agricultores, e destes $45,07 \%$ auxiliam os pais nas atividades a serem desenvolvidas na UPF. Esse auxílio se dá na forma de realização de atividades relacionadas à produção e à manutenção da unidade, em que $46,88 \%$ ajudam uma vez na semana, $43,75 \%$ desenvolvem as atividades duas vezes por semana e 9,37\% trabalham três vezes por semana na propriedade. Esses filhos de agricultores têm entre 16 e 29 anos.

Quanto às atividades desenvolvidas na UPF, verificou-se que as mais realizadas pelos homens são o transporte e a comercialização dos produtos agropecuários, sendo esta desenvolvida em menores proporções pelas mulheres (Tabela 3 ). $\mathrm{O}$ trabalho efetuado pela família ocorre em quase todas as atividades, com exceção do preparo de solo, que é executado apenas pela figura do marido e filhos. Foi observado que algumas atividades são predominantes na figura do gênero masculino enquanto que outras ficavam a cargo dos indivíduos do gênero feminino. Exceto para serviços de banco, quando há predominância feminina para execução dos serviços, observa-se uma relação com o trabalho desenvolvido por todos da família. Essa similitude pode estar associada ao tipo de atividades desenvolvidas pelas mulheres que, na maioria das vezes, estão ligadas à produção de frutíferas e olerícolas e à criação de pequenos animais (frango e suíno).

Uma situação que chama atenção é a forte presença das mulheres na decisão do quê e de onde produzir, o que reforça a alegação de Scheneider (2003), que afirma que é no âmbito da família que se discute e se organiza as inserções produtiva, laboral e moral dos seus diferentes membros e é em função deste referencial que se estabelecem as estratégias individuais e coletivas que visam garantir a reprodução social do grupo.

Tabela 3. Divisão dos trabalhos realizados nas UPF's no assentamento Seringal, comunidade Santa Rosa em Vila Bela da Santíssima Trindade - MT

\begin{tabular}{l|cc|cc|cc|ccc|c}
\hline \multicolumn{1}{c|}{$\begin{array}{c}\text { Atividades desenvolvidas } \\
\text { nas UPF's }\end{array}$} & \multicolumn{2}{|c|}{ Homem } & \multicolumn{2}{c|}{ Mulher } & \multicolumn{2}{c|}{ Filhos } & \multicolumn{2}{c|}{ Família } & \multicolumn{2}{c}{ Total } \\
\cline { 2 - 10 } & $F_{i}$ & $F_{r i}$ & $F_{i}$ & $F_{r i}$ & $F_{i}$ & $F_{r i}$ & $F_{i}$ & $F_{r i}$ & $F_{i}$ & $F_{r i}$ \\
\hline Capina & 34 & 47,88 & 2 & 2,82 & 20 & 28,17 & 15 & 21,13 & 71 & 100 \\
Preparo do Solo & 41 & 57,75 & 0 & 0,00 & 30 & 42,25 & 0 & 0,00 & 71 & 100 \\
Plantio & 32 & 45,07 & 1 & 1,41 & 27 & 38,03 & 11 & 15,49 & 71 & 100 \\
Colheita & 12 & 16,90 & 27 & 38,03 & 12 & 16,90 & 20 & 28,17 & 71 & 100 \\
Decisão de o quê produzir & 5 & 7,04 & 27 & 38,03 & 10 & 14,08 & 29 & 40,85 & 71 & 100 \\
Decisão de onde produzir & 32 & 45,07 & 17 & 23,95 & 10 & 14,08 & 12 & 16,90 & 71 & 100 \\
Reunião de Associação & 30 & 42,25 & 5 & 7,04 & 34 & 47,89 & 2 & 2,82 & 71 & 100 \\
Serviços de Banco & 12 & 16,90 & 20 & 28,17 & 37 & 52,11 & 2 & 2,82 & 71 & 100 \\
Transporte e Comercialização & 40 & 56,34 & 10 & 14,08 & 18 & 25,35 & 3 & 4,23 & 71 & 100 \\
\hline
\end{tabular}

$F_{i}=$ frequência absoluta; $F_{r i}=$ frequência relativa $(\%)$.

Fonte: Os autores (2016). 
652 - Extrativismo e Produção de Alimentos como Estratégia de Reprodução de Agricultores Familiares do Assentamento Seringal, Amazônia Meridional

Estudos realizados por Vieira (2006) revelam que as mulheres são as responsáveis pela implantação e pelo manejo dos quintais. Para Rosa (2002), a divisão de trabalho no universo da agricultura familiar é uma estratégia dos agricultores para maximizar a eficiência da mão de obra familiar. De acordo com esta autora, neste contexto, a mulher representa uma grande força de trabalho na unidade familiar, pois, além das atividades produtivas, ela ainda realiza tarefas domiciliares, que englobam diversos serviços domésticos, inclusive a formação e manutenção dos quintais.

Conforme afirmação de Garcia (2004), o fato de o trabalho feminino ser "improdutivo" do ponto de vista da remuneração econômica relega ao plano da invisibilidade do tempo e energia que as mulheres empregam para o cuidado e atenção das tarefas consideradas como domésticas. Estas que não são expressas em valores monetários são facilmente esquecidas e desvalorizadas pela sociedade.

Analisando a renda anual agrícola dos agricultores familiares foi possível constatar que 36,62\% têm renda anual variando entre R\$10.001,00 e $\mathrm{R} \$ 20.000,00$, enquanto $23,94 \%$ alcançam renda anual de $\mathrm{R} \$ 20.0001,00$ a $\mathrm{R} \$ 30.000,00$. Para $23 \%$ dos agricultores, a renda agrícola anual é menor que $\mathrm{R} \$ 10.000,00$ e em $9 \%$ dos casos essa renda fica entre $\mathrm{R} \$ 30.001,00$ e R $\$ 40.000,00$. Apenas em 3,76\% dos casos os agricultores têm renda agrícola anual acima de $\mathrm{R} \$ 40.000,00$.

A renda agrícola anual desses agricultores familiares está diretamente ligada ao que produzem nas UPF. A origem da renda é bastante diversificada, pois ela é composta por auxílios governamentais (Bolsa Família, aposentadorias e etc.), venda de animais, venda de produtos de roça, comercialização de peixes (provenientes do extrativismo e da piscicultura), empregos no serviço público, venda de cosméticos (elaborados a partir de plantas medicinais, como o caso de produtos capilares à base de babosa), entre outros.

A heveicultura é a principal atividade dos agricultores familiares, pois o assentamento foi constituído com esse intuito há 14 anos, contudo, devido à baixa de preço do quilograma da borracha natural, de cerca de $\mathrm{R} \$ 4,95$ para $\mathrm{R} \$ 1,75$, em 2014 e 2015, respectivamente, a atividade do extrativismo passou a ser secundária no assentamento, deixando os agricultores desanimados. Apesar disso, o extrativismo ainda representa um papel fundamental na reprodução da agricultura familiar no assentamento.
Para grande parte dos agricultores $(62,79 \%)$, a baixa do preço da borracha natural é responsável pela redução na produção desse produto no assentamento. Segundo os agricultores, a concorrência da borracha produzida no assentamento com a de origem de outros países influenciou a queda no preço. Aliado a isso, $37,21 \%$ dos agricultores apontam que a falta de políticas públicas voltadas para o desenvolvimento e exploração de seringais plantados atrapalham o setor nesse momento de crise.

Segundo Santos et al. (2003), a renda de seringueiro, que também é agricultor e vive dos produtos provindos da floresta, é muito pequena, e muitas vezes ele vive em pobreza extrema, e toda vez que não se consegue atingir essa população com programas que verdadeiramente funcionem, coloca-se nos mesmos uma carga de trabalho pesada e sobre-humana. A eficiência dos programas de governo só terá o sucesso esperado quando se conseguir dar um pouco mais de dignidade para os verdadeiros guardiões da floresta.

Para seringais nativos na região Amazônica, existem subsídios que auxiliam os agricultores, principalmente em épocas de baixa de preço no mercado. De acordo com o MEC (2007), a conquista política por parte da produção familiar extrativista de um subsídio federal de até $R \$ 0,90$ por quilograma de borracha natural beneficiada, criado pela Lei no 9.479, de 12/09/97 (BRASIL, 1997), representou um passo muito importante no reconhecimento político institucional das populações extrativistas como sujeitos do desenvolvimento da Amazônia. Essa política federal foi complementada por um subsídio do governo do estado do Acre, de R\$ 0,40 por quilograma de borracha natural bruta para seringueiros organizados em associações, cooperativas ou centrais, recurso criado pela Lei no 1.277, de 13/01/99 - "Lei Chico Mendes" (BRASIL, 1999). Esse exemplo aponta para a elevação dos preços pagos ao agricultor a médio prazo. Atraído pelo incentivo da política de subsídios, observa-se o retorno do seringueiro à atividade, crescendo o número de famílias envolvidas na atividade. Assim, a agricultura familiar é atrativa, pois a extração do látex ocorre cerca de 10 meses no ano e apresenta alta demanda de mão de obra qualificada para realizar a sangria das árvores (ROSSMANN, 2007).

No assentamento Seringal, a frequência de sangria adotada pelos agricultores pesquisados é a cada três e quatro dias ("d/3" e "d/4"), em que estas, em sua 
maioria, são usadas de forma conjunta para acompanhar melhor os dias úteis da semana. Esta frequência está equivalente à recomendada por Virgens-Filho (2007), que afirma que ela vem sendo utilizada principalmente como forma de otimizar a mão de obra no seringal. Porém, esse tipo de manejo pode não extrair o volume máximo de látex da árvore, devido ao menor número de sangrias no ano (SILVA, 2008).

No assentamento Seringal, os cortes e a extração do látex são papéis desenvolvidos majoritariamente pelos homens $(92,82 \%)$. As poucas mulheres que realizam a sangria o fazem por serem a chefe de família da sua unidade de produção. Apesar dessa presença marcante dos homens na extração da borracha, as mulheres também retiram renda dessa atividade, pois são elas as responsáveis pela coleta e seleção das sementes das seringueiras, que são vendidas a outros agricultores e principalmente para o viveiro municipal. Após a formação de mudas no viveiro municipal, elas são doadas a agricultores familiares do município que tenham interesse na atividade.

A atividade extrativista geralmente desempenha caráter secundário em relação à atividade produtiva principal, no que se refere à segurança alimentar e à geração de renda, e em apenas alguns casos é tida como principal atividade desempenhada. De qualquer forma, no Brasil, dada a sua imensa gama de produtos de natureza extrativa e sua densa cobertura florestal, o exame do extrativismo tem grande importância (HIRONAKA, 2000).

Para a manutenção da família, a partir de 2015, os agricultores têm diversificado a produção na UPF, sendo muitas vezes a mulher responsável por desenvolver essas atividades, tendo em vista que $59,30 \%$ dos homens estão desenvolvendo atividades remuneradas fora do assentamento, em fazendas próximas.

A maioria das unidades produtivas (91\%) produz de três a quatro culturas, visando a comercialização do excedente, e de seis a 12 culturas destinadas são exclusivamente à alimentação familiar. Em $9 \%$ das unidades produtivas foi encontrada menor diversificação da produção vegetal, em que os agricultores cultivavam menos que três culturas em sua UPF para a comercialização do excedente, e de quatro a cinco culturas utilizadas na alimentação de sua família.

Além da produção agrícola, 75,58\% dos agricultores desenvolvem sistemas de criação animal dentro das UPF, principalmente de frango caipira para corte $(72,30 \%)$, galinhas poedeiras $(47,69 \%)$, suinocultura $(41,54 \%)$ e pecuária leiteira $(40 \%)$. A criação desses animais, com exceção do gado leiteiro, é realizada para o autoconsumo com venda do excedente. No caso do leite, a atividade é essencialmente desenvolvida para a comercialização. A criação de animais faz parte das atividades que visam autoconsumo para grande parte dos agricultores familiares (HIRAI e SACCO DOS ANJOS, 2007).

A mandioca é cultivada em 91,86\% das UPF, as hortaliças folhosas, em $81,39 \%$, o pepino é cultivado em $46,51 \%$, o milho, em $59,30 \%$, o abacaxi e a batata-doce estão em 51,16\% das UPF, a melancia, em 45,34\%, a abóbora, em $40,70 \%$, a banana-nanica, em $39,53 \%$, a pimenta-bode, em $38,37 \%$ e a pimenta-de-cheiro, em $34,88 \%$.

Ressalta-se a importância da mandioca para a comercialização e na alimentação dos próprios agricultores familiares. Conforme Hoffmann (2014), a mandioca tem lavoura rústica e, para o pequeno agricultor familiar, o produto fica "armazenado" na roça e, quando necessário, ele arranca um ou mais pés de mandioca. Dados do Censo Agropecuário (IBGE, 2006) indicam que apenas $48,9 \%$ da produção de mandioca da agricultura familiar é comercializada e mais da metade é consumida ou processada no próprio estabelecimento.

As espécies anuais, como arroz, milho e mandioca, são importantes social e economicamente para agricultores familiares (MICHELOTI, 2010). Nessa interface, a mandioca e seus derivados desempenham grande participação na renda dos agricultores, apresentando importância econômica relativa de 48,3\% .

A diversificação e a produção para o autoconsumo, neste caso, surgem como uma resposta à uma situação de crise e insegurança, como uma "necessidade de reação", conforme definido por Ellis (2000). São estratégias que visam aumentar a autonomia e minimizar a vulnerabilidade advinda da mercantilização intensa. De modo semelhante, Buainain et al. (2003) afirmam que a diversificação "é uma clara e consciente estratégia de redução de riscos e incerteza, sem dúvida um trunfo de muitos sistemas de produção explorados por agricultores familiares".

Dessa forma, produzir para o autoconsumo é fundamental a esses agricultores familiares como estratégia de reação a uma situação adversa ou necessidade, pois, dessa maneira, a família passa a ter certa autonomia que auxilia na garantia de alimentação, o que consequentemente reduz a exposição desses agricultores aos mercados. Essa produção também tem papel 
654 - Extrativismo e Produção de Alimentos como Estratégia de Reprodução de Agricultores Familiares do Assentamento Seringal, Amazônia Meridional

fundamental na diversificação de renda desses agricultores, potencializando uma estabilidade a esses agricultores através da redução dos efeitos e riscos a qual essa produção possa estar exposta.

Desde a década de 1980, estudos brasileiros demonstravam a necessidade da diversificação da produção, pois, conforme apontado por Lovisolo (1989), uma unidade não diversificada aparece como fraca às crises ecológicas, as quais não afetam da mesma forma todas as culturas; assim, uma unidade diversificada pode resistir melhor a este tipo de situação. Para o autor, a diversificação compreende manter na mesma unidade a produção para autoconsumo e outra atividade com base ou fundamento no capital, que passa pela aquisição de bens de produção e de tecnologias incorporadas.

No caso de assentados de reforma agrária, as famílias têm como maiores objetivo e conquista conseguir o acesso à terra; entretanto, essa conquista não estabelece a permanência desses agricultores no campo, pois, a partir do acesso, grandes desafios se apresentam a esses agricultores, dentre eles as dificuldades de produção, em especial para o autoconsumo, o que reflete diretamente na segurança alimentar nutricional (SAN) familiar. Entende-se por segurança alimentar o direito de todos ao acesso regular e permanente a alimentos de qualidade, em quantidade suficiente, sem comprometer o acesso a outras necessidades essenciais, tendo como base práticas alimentares promotoras de saúde, que respeitem a diversidade cultural e que sejam ambiental, cultural, econômica e socialmente sustentáveis (CONSEA, 2004).

A segurança alimentar é um pressuposto básico para a permanência das famílias em áreas de assentamento, pois esta é uma formação social que têm as características mais adequadas para garantir a SAN em condições sustentáveis para os povos do campo com potencialidades de proporcionar uma alimentação adequada para os grupos domésticos (WANDERLEY, 1996).

Segundo Coury (2004), para atingir uma alimentação equilibrada e de qualidade é preciso complementar aos alimentos de base, como as frutas e hortaliças, os alimentos de origem animal.

A maior parte de tudo que é produzido nas UPF no assentamento Seringal é destinada ao autoconsumo familiar (Tabela 4). Na produção agrícola, 48,84\% dos alimentos são utilizados para esse destino e, na produção pecuária, observa-se uma frequência de 56,99\% para o autoconsumo desses produtos. A comercialização dos produtos agrícolas e pecuários foi uma forma de destinação citada pelos agricultores, apresentando frequências de 5,81\% e 11,64\%, respectivamente. Para os demais agricultores, além do uso desses alimentos no autoconsumo, existe a comercialização do excedente.

Para Chayanov (1974), o recurso às atividades não agrícolas é uma estratégia de alocação da força de trabalho familiar ante os condicionantes da unidade produtiva agrícola e expressa, acima de tudo, a racionalidade que a família imprime às suas atitudes para manter o equilíbrio entre trabalho e consumo e garantir, assim, sua reprodução.

Dessa forma, a produção para autoconsumo faz parte da estratégia de reprodução das famílias rurais. Segundo Maluf et al. (2001), podendo dispor de alguns alimentos produzidos pela família, a renda adquirida com a venda de pequenos excedentes pode fazer frente a outras necessidades, como gastos com saúde, educação, vestuário e habitação.

Leite (2004) considera que a produção agropecuária (agrícola, pecuária, extrativista e aquela resultante de produtos primários beneficiados) produzida em um estabelecimento familiar apresenta diferentes destinos, conforme o produto originado, podendo ser usado

Tabela 4. Destinação da produção agropecuária pelos agricultores familiares, assentados no projeto de assentamento Seringal, região sudoeste de Mato Grosso

\begin{tabular}{l|cc|cc}
\hline \multirow{2}{*}{ Destino da Produção } & \multicolumn{3}{c|}{ Produção Agrícola } & \multicolumn{2}{c}{ Produção Pecuária } \\
\cline { 2 - 5 } & $F_{i}$ & $F_{r i}$ & $F_{i}$ & $F_{r i}$ \\
\hline Autoconsumo & 42 & 48,84 & 49 & 56,99 \\
Autoconsumo e comercialização do excedente & 39 & 45,35 & 27 & 31,39 \\
Comercialização & 5 & 5,81 & 10 & 11,64 \\
Total & $\mathbf{8 6}$ & $\mathbf{1 0 0}$ & $\mathbf{8 6}$ & $\mathbf{1 0 0}$ \\
\hline
\end{tabular}

$F_{i}=$ frequência absoluta; $F_{r i}=$ frequência relativa $(\%)$.

Fonte: Os autores (2016). 
para o consumo da família, para alimentação animal, além de serem comercializados. Segundo o autor, os subprodutos resultantes das atividades podem ser reaproveitados na unidade de produção.

Quanto o destino das olerícolas cultivadas, verificou-se que $61,35 \%$ dos agricultores utilizam para o autoconsumo, 18,6\% produzem para comercialização e 20,05\%, além de consumirem, comercializam o excedente da produção. Entre os agricultores que utilizam as olerícolas para autoconsumo, 53,45\% afirmam que essa produção atende às necessidades alimentares desse tipo de alimento, 27,42\% dizem que nem sempre atende, tendo que ser complementados por produtos adquiridos em outras unidades produtoras ou até mesmo em supermercados e feiras livres da cidade. Apurou-se que, para $19,13 \%$ dos agricultores, as olerícolas que cultivam não atendem às suas necessidades de consumo.

O fato de que o cultivo de olerícolas não atende às necessidades familiares de consumo pode estar ligado aos grupos de olerícolas escolhidas para o plantio, em que $92 \%$ dos agricultores optam por grupos de interesse comercial. Segundo Grisa (2007), a mercantilização da agricultura interfere na produção para autoconsumo, pois os agricultores são incitados a produzir produtos comerciais, visíveis e sancionados pelo mercado, em que as propriedades familiares reduzem o tempo e o espaço dedicados a esse tipo de produção.
Nesse contexto, Sacco dos Anjos (2003) reforça que esta "reconversão forçada" dos agricultores incita a passagem de policultores para "tributários do regime monocultivo", cingidos pela especialização produtiva e pelo abandono da produção para autoconsumo.

Contrapondo essa produção que atenda exclusivamente o mercado, Leite (2004), aponta que a produção para o consumo familiar confere um efeito anticíclico, compensando as épocas de baixos rendimentos monetários nos estabelecimentos e as variações destes ao longo do ano, o que proporciona uma renda total mais constante. De tal forma, a produção visando o autoconsumo é, portanto, um importante "instrumento de proteção frente às incertezas e oscilações da produção mercantil" (MALUF et al., 2001)

A produção de hortaliças, segundo Filgueira (2007), estabelece uma relação do agricultor com a terra, de sustentação familiar e da cultura alimentar, sendo este mesmo espaço importante para o desenvolvimento econômico e social da família.

As principais olerícolas cultivadas pelos agricultores familiares do assentamento Seringal são cebola de folha, alface, couve, abobrinha, pepino, jiló, rúcula, quiabo, pimentão, pimenta-de-cheiro, tomate, salsinha, coentro, repolho e almeirão (Tabela 5).

Queiroz et al. (2015) observaram que, em Curvelândia, município integrante da região sudoeste

Tabela 5. Principais olerícolas cultivadas para comercialização e autoconsumo pelos agricultores familiares em Vila Bela da Santíssima Trindade - MT

\begin{tabular}{|c|c|c|c|c|c|}
\hline \multirow{2}{*}{ Espécies cultivadas } & \multirow{2}{*}{ Nome científico } & \multicolumn{2}{|c|}{ Autoconsumo } & \multicolumn{2}{|c|}{ Comercialização } \\
\hline & & $F_{i}$ & $F_{r i}$ & $F_{i}$ & $F_{r i}$ \\
\hline Alface & Lactuca sativa & 73 & 14,01 & 13 & 4,63 \\
\hline Cebola de Folha & Allium fistulosum & 67 & 12,86 & 29 & 10,32 \\
\hline Quiabo & Abelmoschus esculentus (L.) & 54 & 10,36 & 39 & 13,88 \\
\hline Berinjela & Solanum melongena (L.) & 49 & 9,4 & 37 & 13,17 \\
\hline Pimentão & Capsicum annuum (L.) & 45 & 8,64 & 18 & 6,4 \\
\hline Tomate & Solanum lycopersicum & 44 & 8,46 & 30 & 10,68 \\
\hline Abobrinha & Cucúrbita máxima & 40 & 7,68 & 9 & 3,2 \\
\hline Rúcula & Eruca sativa & 27 & 5,18 & 21 & 7,47 \\
\hline Couve & Brassica oleracea (L.) & 19 & 3,65 & 17 & 6,05 \\
\hline Jiló & Solanum gilo Raddi & 17 & 3,26 & 11 & 3,92 \\
\hline Pimenta-Bode & Capsicum chinense & 17 & 3,26 & 15 & 5,34 \\
\hline Pimenta-de-Cheiro & Capsicum odoriferum & 17 & 3,26 & 12 & 4,27 \\
\hline Pepino & Cucumis sativus (L.) & 12 & 2,3 & 9 & 3,2 \\
\hline Salsinha & Petroselinum crispum & 12 & 2,3 & 5 & 1,78 \\
\hline Coentro & Coriandrum sativum & 10 & 1,92 & 5 & 1,78 \\
\hline Almeirão & Cichorium intybus intybus & 9 & 1,73 & 5 & 1,78 \\
\hline Repolho & Brassica oleracea & 9 & 1,73 & 6 & 2,13 \\
\hline Total & & 521 & 100 & 281 & 100 \\
\hline
\end{tabular}

$F_{i}=$ frequência absoluta; $F_{r i}=$ frequência relativa $(\%)$.

Fonte: Os autores (2016). 
656 - Extrativismo e Produção de Alimentos como Estratégia de Reprodução de Agricultores Familiares do Assentamento Seringal, Amazônia Meridional

de Mato Grosso, as espécies hortícolas cultivadas pelos agricultores e comercializadas via Programa de Aquisição Alimentos (PAA) são: abóbora, mandioca, pepino, jiló, quiabo, berinjela, cenoura, cenoura, coentro, alface, almeirão, rúcula, milho, cebolinha, melão, salsinha, abobrinha, beterraba, batata-doce, vagem, pimentão, milho verde, tomate, tomate-cereja, maxixe, feijão-de-corda, couve, pimenta, rabanete, pimenta-doce, melancia, amendoim, yura, couve-chinesa e cachi.

Os autores seguem afirmando que a tomada de decisão dos agricultores de que espécie cultivar está relacionada à rusticidade, ao domínio de técnicas de cultivares e à demanda de mercado, que são os casos do quiabo, cebolinha e alface. Esses fatores também foram encontrados na pesquisa de Vieira (2006), em que as tomadas de decisão ocorreram de acordo com a falta do produto no mercado, propaganda, facilidade de produção e rapidez de produção.

Quando se trata das atividades ligadas à produção desenvolvida nas UPF's, Tedesco (1999) aponta que a força de trabalho do agricultor familiar reproduz-se em nível familiar, não individual. Assim, a combinação do trabalho feminino com o masculino reduz custos familiares na contratação de mão de obra provinda de fora da unidade de produção, redefine as relações locais de trabalho, desorganiza e (re)organiza a divisão familiar do trabalho.

No assentamento Seringal, observa-se que as mulheres "donas de casa", desempenham papel fundamental no estabelecimento de produção de olerícolas, conforme pode ser observado na Tabela 6 , sendo responsáveis principalmente pela atividade de manutenção da horta e da colheita das olerícolas. Indivíduos do sexo masculino, identificados como "pais" nessa pesquisa, são responsáveis pela manutenção da horta em apenas 5,81\% das UPF's e da colheita em apenas $6,98 \%$.

Entretanto, apesar da divisão de trabalho nessas unidades de produção, ainda é possível observar certa desvalorização quanto ao trabalho da mulher, em atividades relacionadas à produção, que é considerada como sendo menor em relação ao trabalho que o homem desempenha, mesmo que o tempo de trabalho dos dois seja praticamente o mesmo, ainda se tem na cabeça a ideia de que a mulher apenas "auxilia" ou "ajuda" o homem nessas atividades. Isso pode ser verificado na fala do Sr. 11:

"O trabalho dos homens é feito em produção maior, entende? A gente cria gado, tem que cuidar do pasto, das vacas. A gente tira o látex, faz o corte da seringa e recolhe a borracha, a gente vende. As donas ficam com a casa, os filho e o quintal, fruta e horta é no quintal, o que dá pra gente vender a gente vende, senão a gente come ou dá pros vizinhos, parentes..." (Entrevista com o Sr. 11, assentamento Seringal, Vila Bela da Santíssima Trindade).

De acordo com Costa e Ralisch (2013), o trabalho da mulher no campo é desvalorizado pois as atividades realizadas por elas são consideradas mais leves, percebidas mais como uma ajuda dentro da propriedade

Em 76\% das UPF's do assentamento Seringal, as mulheres exercem carga horária igual ou superior à dos homens, considerando que as mesmas conciliam os afazeres domésticos com a manutenção da horta, pomar, criação de pequenos animais e colheita de produtos agrícolas. Além dessas atividades, 37\% ainda fabricam doces, farinha de mandioca, queijos e requeijões, que são consumidos pela própria família e vendi-

Tabela 6. Divisão do trabalho de manutenção da horta de colheita das olerícolas produzidas nas UPF do projeto de assentamento Seringal em Vila Bela da Santíssima Trindade - MT

\begin{tabular}{l|cc|cc}
\hline \multirow{2}{*}{$\begin{array}{c}\text { Responsável } \\
\text { pela horta }\end{array}$} & \multicolumn{2}{c|}{ Manutenção } & \multicolumn{2}{c}{ Colheita } \\
\cline { 2 - 5 } & $F_{i}$ & $F_{r i}$ & $F_{i}$ & $F_{r i}$ \\
\hline Mãe & 55 & 63,95 & 25 & 29,07 \\
Todos da família & 16 & 18,61 & 40 & 46,51 \\
Filhos & 10 & 11,63 & 15 & 17,44 \\
Pai & 5 & 5,81 & 6 & 6,98 \\
Total & $\mathbf{8 6}$ & $\mathbf{1 0 0}$ & $\mathbf{8 6}$ & $\mathbf{1 0 0}$ \\
\hline
\end{tabular}

$F_{i}=$ frequência absoluta; $F_{r i}=$ frequência relativa $(\%)$.

Fonte: Os autores (2016). 
dos para estabelecimentos comerciais de Vila Bela da Santíssima Trindade.

Segundo Araújo e Scalon (2005), a existência de relações de gênero marcadas por uma hierarquia entre os sujeitos - assumindo os homens posição dominante - e por uma divisão de atribuições assimétricas valorizadas - a divisão sexual do trabalho, ficando as mulheres responsáveis pela reprodução e pelas tarefas domésticas, que são esferas menos valorizadas, e os homens, pelo que se denominou esfera da produção e pelas atividades conduzidas na vida pública, ambas mais valorizadas na vida social.

O fato de que o trabalho desenvolvido pelas mulheres seja improdutivo do ponto de vista da remuneração econômica faz com que o tempo e a energia empregados por elas nos afazeres domésticos e cuidados com os quintais caia na invisibilidade. Dessa forma, estas atividades que geralmente não são expressas em valores monetários acabam facilmente esquecidas e desvalorizadas pela sociedade (GARCÍA, 2004).

A motivação para o autoconsumo pode ser variada (Tabela 7). Para a maioria dos agricultores a motivação para a produção para autoconsumo se dá pela redução de despesas relacionadas à compra de alimentos; pela disponibilidade de alimento em fartura e em quantidade, variedade e qualidade, visto que, segundo afirmações desses agricultores, "comer o que se produz é mais confiável, porque sabemos como a gente produz..." (Entrevista com o Sr. 24); e como forma de se obter e manter a soberania alimentar dessas famílias. Os agricultores familiares utilizam o termo "segurança alimentar"; entretanto, não conhecem as diretrizes para esse princípio e não conseguem atender a estes apenas com a sua produção de alimentos. Dessa forma, adotou-se a terminologia de soberania alimentar, de maneira que refletisse a realidade dessas famílias.
Segundo Gazolla (2006), a importância principal da produção para autoconsumo está relacionada com possuir alimentos em quantidades suficientes para alimentar a família. Assim, conforme o autor, a produção para autoprovisionamento preenche o princípio da segurança alimentar, evitando que os agricultores passem fome ou por restrições alimentares.

De acordo com Niederle et al. (2014), mais do que produzir alimentos em quantidade, a agricultura familiar também passou a ser reconhecida pela sua contribuição à soberania e segurança alimentar e nutricional, tornando-se uma opção estratégica para tentar reverter uma verdadeira epidemia na saúde pública, a qual se expressa nas inúmeras doenças que decorrem das drásticas transformações nos padrões de consumo alimentar.

Conforme levantado durante as entrevistas, $85,92 \%$ dos agricultores apontam a produção para autoconsumo como essencial, afirmando que, sem essa produção, teriam dificuldades para se manter nas unidades de produção. Este fato pode ser constatado em um trecho da entrevista com a Sra 21 :

"Quando a gente foi preciso parar com a tirada da borracha, era um dinheiro certo, sabe, mas aí com a crise, se a gente não tivesse horta, mandioca, fruta e principalmente galinha e porco, a gente tinha passado necessidade e tinha que ter ido tentar alguma coisa na cidade. Como a gente tinha o que comer e o que trocar com os amigos, deu pra segurar até a gente ter produção pra vender e o véio arrumar emprego na fazenda aqui perto..." (Trecho da entrevista com a Sr ${ }^{\mathrm{a}}$ 21).

Segundo Gazolla (2006), a produção para autoconsumo é de extrema importância para os agricultores

Tabela 7. Motivação que leva os agricultores familiares do projeto de assentamento Seringal a produzir para o autoconsumo

\begin{tabular}{l|cc}
\hline \multirow{2}{*}{ Motivação para produção para autoconsumo } & \multicolumn{2}{c}{ Manutenção } \\
\cline { 2 - 3 } & $F_{i}$ & $F_{r i}$ \\
\hline Soberania alimentar & 43 & 50,0 \\
Redução de despesas & 35 & 40,70 \\
Fartura de alimentos & 8 & 9,30 \\
Total & $\mathbf{8 6}$ & $\mathbf{1 0 0}$ \\
\hline
\end{tabular}

$F_{i}=$ frequência absoluta; $F_{r i}=$ frequência relativa $(\%)$.

Fonte: Os autores (2016). 
658 - Extrativismo e Produção de Alimentos como Estratégia de Reprodução de Agricultores Familiares do Assentamento Seringal, Amazônia Meridional

familiares, principalmente em termos de gerar a segurança alimentar para esses agentes, devido ao fato de ela propiciar a geração de alguns princípios norteadores do conceito de agricultura familiar. Para Ellis (2000), a produção para autoconsumo explica a permanência dos agricultores familiares no campo e a reprodução social da agricultura familiar.

A relevância do autoconsumo para a segurança alimentar, como bem discutiu Gazolla (2006), pode ser outro fator, pois essa produção permite acesso facilitado, sem nenhum processo de intermediação por meio de valores de troca, a um conjunto diversificado de alimentos capazes de fornecer os mais diversos nutrientes que o organismo humano necessita. Além disso, a produção para autoconsumo tem sido instrumento de preservação da cultura desses grupos, pois, na decisão do que se produzir, consideram-se as preferências alimentares dessas comunidades e suas práticas de preparo e consumo, sendo este conhecimento repassado por gerações.

De acordo com Grisa e Schneider (2008), a produção para o autoconsumo permite acesso facilitado, sem nenhum processo de intermediação por meio de valores de troca, a um conjunto diversificado de alimentos capazes de fornecer os mais diversos nutrientes que o organismo humano necessita.

Para Grisa (2014), a produção para o autoconsumo cumpre uma importante função ao manter internamente à unidade familiar a satisfação de uma das necessidades principais à reprodução social, a alimentação. Ainda segundo a autora, os agricultores familiares, quando produzem alimentos, sentem-se valorizados ao identificar a sua prática como importante para a manutenção das pessoas no campo. Neste contexto, de acordo com apontamentos de Gazolla e Schnneider (2005), o fortalecimento da produção para autoconsumo em propriedades familiares é impor- tante para que haja o estímulo ao grupo familiar através de um processo de geração da segurança alimentar a nível interno das unidades de produção.

Após determinada a importância dessa produção, questionou-se aos agricultores se eles, sob alguma circunstância, deixariam de produzir para autoconsumo. A partir dessa questão foi possível verificar (Tabela 8) que a maior parte dos agricultores familiares do assentamento Seringal não deixaria de produzir com a finalidade de autoconsumo sob nenhuma hipótese. Observou-se que alguns agricultores só deixariam de produzir para autoconsumo em caso de doença que os impossibilitasse de produzir, enquanto que outros somente o fariam se houvesse a necessidade de deixar a propriedade. Dessa forma, fica explicita a importância da produção de autoconsumo para os agricultores familiares, principalmente pelo cunho cultural, pois a vontade de manter essa produção é intrínseca e remete aos conhecimentos deixados por seus antepassados.

\section{Conclusão}

A extração de látex, apesar de ter sido uma boa estratégia de reprodução e permanência dos agricultores no campo por muito tempo, tem sofrido atualmente com as oscilações de preço de mercado e tem se transformado em um problema a esses agricultores familiares. Uma solução plausível para a situação apresentada seria a proposição de políticas públicas que atendessem não apenas a seringueiros que extraem em florestas nativas, como ocorre atualmente, mas a extensão dessas políticas paras contemplar os seringais plantados. Entretanto, essa não é uma solução que depende exclusivamente dos agricultores. Assim, uma alternativa rápida e palpável a esses agricultores seria utilizar a cadeia produtiva do látex como uma atividade secun-

Tabela 8. Motivação pela qual os agricultores familiares do projeto de assentamento Seringal em Vila Bela da Santíssima Trindade deixariam de produzir para o autoconsumo

\begin{tabular}{l|c|c}
\hline \multicolumn{1}{c|}{ Deixar de Produzir para o autoconsumo } & $\boldsymbol{F}_{\boldsymbol{i}}$ & $\boldsymbol{F}_{\boldsymbol{r}}$ \\
\hline Não deixaria & 41 & 47,67 \\
Doença & 32 & 37,21 \\
Sair da propriedade & 13 & 15,12 \\
Total & $\mathbf{8 6}$ & $\mathbf{1 0 0}$ \\
\hline
\end{tabular}

$F_{i}=$ frequência absoluta; $F_{r i}=$ frequência relativa $(\%)$.

Fonte: Os autores (2016). 
dária e diversificar seu sistema de produção, pois em sistemas diversificados, os agricultores têm maior facilidade para o enfrentamento dessa crise da borracha.

A produção diversificada, voltada principalmente para o autoconsumo desses agricultores familiares, mostrou-se como forma de garantia da manutenção desses agricultores na área rural, principalmente pelo fato de garantir ao que eles chamam de "segurança alimentar" ou disponibilidade básica de alimentos. A criação de pequenos animais e a presença de hortas nessas unidades de produção têm contribuído para a oferta de alimentos em quantidade satisfatória, com a redução de despesas, e com a geração de renda para essas famílias, que encontrou nessa produção uma forma de se reproduzirem no campo.

\section{Referências}

AB'SÁBER, A. N. Bases para o estudo dos ecossistemas da Amazônia brasileira. Estudos Avançados, São Paulo, v. 16, n. 45, p. 7-30, 2002.

ARAÚJO, C. e SCALON, C. (Org.). Gênero, família e trabalho no Brasil. Rio de Janeiro: Editora da FGV, 2005. 323p.

BRASIL. Lei no 9479 de 12 de agosto de 1997. Dispõe sobre a concessão de subvenção econômica a produtores de borracha natural e dá outras providências, 1997.

. Lei no1277 de 13 de janeiro de 1999. Dispóe sobre a concessão de subvenção econômica aos produtores de borracha natural bruta do Estado do Acre e dá outras providências, 1999.

BUAINAIN, A. M., ROMEIRO, A. R. e GUANZIROLI, C. Agricultura familiar e o novo mundo rural. Sociologias, Porto Alegre, v. 5, n. 10, p. 312-347, jul./dez. 2003.

CANOVA, L. Antonio Rolim de Moura: um ilustrado na capitania de Mato Grosso. Coletâneas do Nosso Tempo, Cuiabá, v. 7, n. 8, p. 75-86, ago./dez. 2008.

CARVALHO, D. F. Financiamento do FNO e seus impactos financeiros e socioeconômicos na indústria da Região Norte. In: SANTANA, A. C. (Coord). O Fundo constitucional de financiamento do norte e o desenvolvimento da Amazônia. M\&S Editora, Belém-PA, 2002. 623 p.

CHAYANOV, A. V. La organización de la unidad económica campesina. Buenos Aires. Nueva Visión, 1974, 120p.

CONSEA. II Conferência Nacional de Segurança Alimentar e Nutricional "A construção do conceito de segurança alimentar e nutricional", Anais..., Brasília: CONSEA, 2004.

COSTA, F. L. M. e RALISCH, R. A juventude rural do Assentamento Florestan Fernandes no Município de Florestópolis (PR). Revista Economia e Sociologia Rural, Piracicaba, SP, v. 51, n 3, p. 415-432, jul./set. 2013.

COURY, S, T. Nutrição vital: uma abordagem holística de alimentação e saúde. Brasília: LGE Editora, 2004. 285p.

CUNHA, J. M. P. Migrações no Centro-Oeste brasileiro: as tendências e características do período de 1986-1996. Encontro De Demografia Da Região Centro-oeste, 2. Anais... Brasília: Codeplan/ FNUAP, 2000.

DESER. Departamento de Estudos Socioeconômicos Rurais. Referência de desenvolvimento da agricultura familiar da região Sul/Brasil - construção metodológica de uma matriz produtiva sustentável. Projeto rede Brasil de agricultores gestores de referência da agricultura da região Sul do Brasil. Deser, Relatório 2003/2004.

DRUMMOND, J. A. A extração sustentável de produtos florestais na Amazônia brasileira: vantagens, obstáculos e perspectivas. Revista Estudos Sociedade e Agricultura, Rio de Janeiro, v. 6, p. 115-137, 1996.

DUARTE, R. Entrevistas em pesquisas qualitativas. Educar, Curitiba, n. 24, p. 213-225, 2004.

ELLIS, F. Rural livelihoods and diversity in developing countries. Oxford: Oxford University Press, 2000. 279p.

FERREIRA, B. e ALVES, F. Juventude rural: alguns impasses e sua importância para a agricultura familiar. In: CASTRO, J. A., AQUINO, L. M. C. e ANDRADE, C. C. (Orgs.). Juventude e políticas sociais no Brasil. Brasília: IPEA, 2009. p. 241-258.

FILGUEIRA, F. A. R. Novo manual de olericultura: agrotecnologia moderna na produção e comercialização de hortaliças. 3. ed. Viçosa, MG: UFV, 2007. 421p.

GARCIA, F. M. A luta pela terra sob enfoque de gênero: os lugares da diferença no Pontal do Paranapanema. 2004. $224 \mathrm{f}$. Tese (Doutorado em Geografia) - Faculdade de Ciência e Tecnologia, Universidade Estadual Paulista Júlio de Mesquita Filho, Presidente Prudente, 2004.

GAVIOLI, F. R. e COSTA, M. B. P. As múltiplas funções da agricultura familiar: um estudo no assentamento Monte Alegre, região de Araraquara (SP). Revista de Economia e Sociologia Rural, Brasília, v. 49, n. 2, p. 449472, 2011.

GAZOLLA, M. O processo de mercantilização do consumo de alimentos na agricultura familiar. In: SCHNEIDER, S. (Org.). A diversidade da agricultura 
660 - Extrativismo e Produção de Alimentos como Estratégia de Reprodução de Agricultores Familiares do Assentamento Seringal, Amazônia Meridional

familiar. Editora da UFRGS: Porto Alegre, 2006. p. 32-39. (Coleção Estudos Rurais)

GAZOLLA, M. e SCHNEIDER, S. As duas "caras" do PRONAF: produtivismo ou fortalecimento da produção para autoconsumo? In: XLIII Congresso da Sociedade Brasileira de Economia e Sociologia Rural, Ribeirão Preto - SP. Anais... CD-ROM, 2005, 21 p.

GOMES, I. Sustentabilidade social e ambiental na agricultura familiar. Revista de Biologia e Ciências da Terra, Paraíba, v. 5, n. 1, p. 2-17, 2004.

GRISA, C. As ideias na produção de políticas públicas: contribuições da abordagem cognitiva. In: BONNAL, P. e LEITE, S. P. (Orgs.). Análise comparada de políticas agrícolas: uma agenda em transformação. Rio de Janeiro: Cirad/Mauad, 2007. p. 93- 137.

e SCHNEIDER, S. Plantar pro gasto: a importância do autoconsumo entre famílias de agricultores do Rio Grande do Sul. Revista de Economia e Sociologia Rural, v. 46, n. 2, p. 481-515, jun. 2008.

WESZ JR., V. J. e BUCHWEITZ, V. D. Revisitando o Pronaf: velhos questionamentos, novas interpretações. Revista de Economia e Sociologia Rural, Piracicaba, v. 52, n. 2, p. 323-346, 2014.

HIRAI, W. G. e ANJOS, F. S. Estado e segurança alimentar: alcances e limitações de políticas públicas no Brasil. Revistas Textos e Contextos, Porto Alegre, v. 6, n. 2, p. 335-353, 2007.

HIRONAKA, G. M. F. N. O extrativismo como atividade agrária. Jus Navigandi, Teresina, v. 4, n. 42, 2000.

HOFFMANN, R. A agricultura familiar produz $70 \%$ dos alimentos consumidos no Brasil? Revista Segurança Alimentar e Nutricional, Campinas, v. 1, n. 21, p. 417-421, 2014.

IBGE. Censo Demográfico 2010. Instituto Brasileiro de Geografia e Estatística. Disponível em: <http://www. ibge.gov.br/censo2010/> . Acesso em: 15 dez. 2015.

Censo Agropecuário 2006. Agricultura Familiar - Primeiros Resultados - Brasil, Grandes Regiões e Unidades da Federação. Rio de Janeiro: Instituto Brasileiro de Geografia e Estatística, 2009. Disponível em: <https://biblioteca.ibge.gov.br/visualizacao/ periodicos/50/agro_2006_agricultura_familiar.pdf $>$. Acesso em: 15 dez. 2015

LEITE, S. P. Autoconsumo y sustentabilidad en la agricultura familiar: una aproximación a la experiencia brasileña. In: BELIK, W. (Ed.). Politicas de seguridad alimentaria y nutrición en América Latina. São Paulo: Hucitec, 2004. p. 123-181.
LIMA, A. C. et al. Quintal espaço de saberes e de segurança alimentar no Vale do Guaporé, Amazônia Meridional, Mato Grosso. Revista de Estudos Sociais, v. 17. n. 34, p. 139-148, 2015.

LOVISOLO, H. Terra, trabalho e capital: produção familiar e acumulação. Campinas, SP: Editora da UNICAMP, 1989. 82 p.

MALUF, R., MENEZES, F. e MARQUES, S. Caderno Segurança Alimentar. Montpelier: Fondation Charles Léopold Mayer pour le Progrès de l'Homme, Red Agriculturas Campesinas, Sociedades y Globalización (APM). São Paulo, editora: Instituto Polis, 2001, 67p.

MEDEIROS, L. e LEITE, S. A formação dos assentamentos rurais no Brasil: Processos Sociais e Políticas Públicas. Rio de Janeiro: Ed. Universidade UFRGS/CPDA, 1999. 307p.

MELO, H. P. e SABBATO, A. O feminino no mundo rural: um olhar pela PNAD/IBGE. In: Congresso Mundial de Sociologia Rural, 10; Congresso Brasileiro de Economia e Sociologia Rural, 38, 2000, Rio de Janeiro. Anais... Brasília: SOBER, 2000. 1 CD-ROM.

MENDES, M. F. et al. O Programa de Aquisição de Alimentos da agricultura familiar nos assentamentos da região sudoeste mato-grossense. Revista: Cadernos de Agroecologia, Belém/PA, v. 8, n. 2, 2013.

MENDONÇA, R. História de Mato Grosso. Cuiabá: Fundação Cultural de Mato Grosso, 1982. 400p.

MINAYO, M. C. S. Pesquisa social: teoria método e criatividade. 16. ed. Petrópolis: Vozes, 2000. 108p.

NIEDERLE, P. A., FIALHO, M. A. V. e CONTERATO, M. A. A pesquisa sobre agricultura familiar no Brasil - aprendizagens, esquecimentos e novidades. Revista Economia e Sociologia Rural, Piracicaba-SP, v. 52, n. 1, p. 009-024, 2014.

QUEIROZ, R. F. N. Análise agroclimática do melão na região Sudoeste Mato-grossense. Revista Brasileira de Geografia Física, Pernambuco, v. 9, n. 1, 2016.

RIBEIRO, E. M. e OLIVEIRA, L. Ocupação e emprego na agropecuária mineira nos anos 90. Revista de Economia Rural, Viçosa-MG, v. 9, n. 6, p. 29-34, 1999.

ROSA, L. S. Limites e possibilidades do uso sustentável dos produtos madeireiros na Amazônia Brasileira: o caso dos pequenos agricultores da vila Boa Esperança, em Mojú, no Estado do Pará. 2002. 304p. Tese (Doutorado em Desenvolvimento Sustentável do Trópico Úmido) AEA, Universidade Federal do Pará, Belém, 2002.

SACCO DOS ANJOS, F. Agricultura familiar, pluriatividade e desenvolvimento rural no sul do Brasil. Pelotas, RS: EGUFPEL, 2003. 374 p. 
SANT'ANA, A. L. Raízes na terra: as estratégias dos produtores familiares de três municípios da mesorregião de São José do Rio Preto (SP). 2003. 246p. Tese (Doutorado em Sociologia) - Faculdade de Ciências e Letras, Universidade Estadual Paulista, Araraquara, SP, 2003.

SANTOS, J. C. et al. Estimativa de Custo de Coleta e Rentabilidade para Sistema Extrativo de Látex de Seringueira no Acre, Safra 2001/2002. Rio Branco, 2003. (Embrapa Acre. Comunicado Técnico 157).

SCHNEIDER, S. Agricultura familiar e pluriatividade. A pluratividade na agricultura familiar. Porto Alegre: UFRGS, 2003. p. 73-110.

SILVA, J. Q. Sistemas de explotação e clones de seringueira: caracteres agronômicos e viabilidade econômica.
2008. 117p. Dissertação (Mestrado em Tecnologia da Produção Agrícola) - Instituto Agronômico de Campinas, Campinas, 2008.

TEDESCO, J. C. Terra, trabalho e família: racionalidade produtiva e ethos camponês. Passo Fundo, RS: EDIUPF, 1999. $331 \mathrm{p}$.

VIEIRA, T. A. Sistemas agroflorestais em áreas de agricultores familiares no município de Igarapé-Açu, Pará: adoção, composição florística e gênero. 2006. 102p. Dissertação (Mestrado em Ciências Florestais) - Universidade Federal Rural da Amazônia, Belém, 2006.

VIRGENS-FILHO, A. C. Exploração de seringais. Informe Agropecuário, Belo Horizonte, v. 28, n. 237, p. 105-119, 2007.

Todo o conteúdo deste periódico, exceto onde estiver identificado, está licenciado sob uma Licença Creative Commons (cc by 4.0). 
